\title{
COMUNIDADE E ESCOLA, MEMÓRIA E PRODUÇÃO CULTURAL
}

\section{Projeto de pesquisa abre a escola à comunidade e faz dela centro de produção e memória de comunicação e cultura}

Com o apoio do $\mathrm{CNPq}$ (Conselho Nacional de Desenvolvimento Científico e Tecnológico) e da FAPESP (Fundação de Amparo à Pesquisa do Estado de São Paulo), tem início uma parceria ECAUSP/Escola pública paulistana para o estudo sistemático dos contos, dos casos populares, das histórias de vida, da animação da escola e de sua vizinhança, para a recolha da memória periférica paulistana, sua organização em tipos e motivos, para publicação, introdução ao enriquecimento das disciplinas escolares e devolução à comunidade para estimulação de processos similares em outros espaços de trabalho.

A Escola Estadual de Primeiro Grau Raul Fonseca, dirigida pelo Prof. Oldack Chaves, participa do projeto ao lado do Departamento de Comunicações e Artes da ECA-USP e seu Núcleo de Informática para Comunicações e Artes (NICA). Participam também do projeto os professores de primeiro grau José Ferreira Ramos Neto,

\section{O AUTOR}

Luís Roberto Alves

Professor Doutor do Departamento de Comunicações e Artes da ECA-USP. Pesquisador e Assessor de Movimentos Sociais. E-mail: luralve@usp.br
Maria do Socorro Barbosa e Ivânia Paula Barros de Almeida. A escola de primeiro grau se localiza no Jardim da Saúde e serve às comunidades de Parque Bristol, Clímax, Vila das Mercês, Moinho Velho e Favela de Heliópolis, no espaço entre São Paulo, São Caetano do Sul e São Bernardo do Campo. Tem cerca de 20 anos e comporta 1.400 estudantes. Na recente reorganização administrativa a que foi submetida, atenderá estudantes de quinta à oitava séries, idade ideal para a experiência que propomos desenvolver neste projeto. Seus 40 professores se distribuem em três períodos de trabalho, com jornadas variáveis entre 20 e 32 aulas por semana. A escola tem alguma história de preocupação com a comunidade, realização de algumas festas e trabalhos isolados de recuperação de memória popular. $\mathrm{O}$ convite ao pesquisador-proponente para orientar reflexões sobre memória e cultura possibilitou a preparação do presente projeto, para o qual a comunidade escolar já se prepara.

Com base nas categorias fundamentais de memória e cidade, mediação cultural e lugar da existência produtiva, o projeto terá exigências modestas de infra-estrutura, envolverá centenas de estudantes, depois de preparados para o ato de ouvir e 
registrar o conhecimento de seus pares e dos mais idosos, permitirá reflexões sobre folclore, memória histórica, formas e sentidos dos discursos populares, defeitos e virtudes dos livros didáticos em seus discursos sobre a história, mediação cultural da memória na sociedade em que a mídia é produtora privilegiada de sentidos e valores sociais.

Permitirá, fundamentalmente, à comunidade escolar rever-se como centro de cultura, lugar ecumênico de criação simbólica, espaço para a crítica da cultura de massa e das formas tradicionais de vida na dinâmica urbana.

O projeto se cumpre a partir de uma relação de amizade e afinidade entre os pesquisadores locais e o pesquisador universitário (também professor de primeiro e segundo graus durante 18 anos), projetando a presença do Instituto de Estudos Avançados da USP e do Departamento de Comunicações e Artes da ECA-USP na vida cotidiana da escola, com base na preocupação do Grupo de Educação e Escola Pública do Instituto de Estudos Avançados da USP, denominado Paidéia (Sistema e Filosofia de Educação da Grécia antiga, século V a.C) e seus estudos sobre a escola pública, seus métodos de ensino-aprendizagem, sistemas de avaliação, ação cultural e caminhos determinados pela nova LDB (Lei de Diretrizes e Bases) e recentes reformulações da rede física paulista.

\section{MEMÓRIA E MODERNIZAÇÃO}

A banalização das modernizações enseja torcer o nariz para os estudos de memória cultural e das variações das culturas populares em face da criação das elites, muito mais socialmente aprovadas. Quando foi necessário pensar a transição democrática nos anos 70/80, fez-se moda estudar o popular. No entanto, a vitória do neoliberalismo e da concorrência mercantil estimula meter o tema no ostracismo. Pensar e sondar a memória não é apenas um tema importante, mas sim compromisso com mudanças em um país campeão de injustiças sociais.

Convém perguntar se esse tema perdeu $o$ valor. O que fundamentalmente mudou no Brasil que inviabilize o estudo das mediações culturais na análise da comunicação social? Quais resíduos das culturas migrantes serão importantes para a compreensão das audiências de telenovela, para a verificação dos gostos e preferências dos públicos jovens perante o mundo da imagem? E o que ainda têm a oferecer as expressões culturais tradicionais para sedimentar a passagem para a sociedade midiática?

É verdade que ainda não temos uma sociedade midiática por excelência. Por isso, os chamados estudos culturais, a sociologia da cultura, os textos clássicos sobre as mediações culturais são relidos e acrescentados de novos textos, na seqüência de Paul Thompson, Ecléa Bosi, Williams, Bom Meihy, Lucrécia Ferrara, Bourdieu, edições do Instituto Pólis ${ }^{1}$ em São Paulo etc. Os

1. BOSI, Ecléa. Memória e sociedade. Lembrança de velhos. São Paulo: EDUSP/T.A. Queiroz, 1987.

Cultura de massa e cultura popular. Leituras de operárias. Petrópolis: Vozes, 1972. BOURDIEU, Pierre. O poder simbólico. São Paulo: Difel, 1989. BRANT, Vinícius Caldeira. (coord.) São Paulo: trabalhar e viver. São Paulo: Comissão de Justiça e Paz de São Paulo/Brasiliense, 1989. CERTEAU, Michel de. A cultura no plural. Campinas: Papirus, 1995. THOMPSON, Paul. A voz do passado. História Oral. Rio de Janeiro: Paz e Terra, 1992. MEIHY, José Carlos S. Bom. Manual de História Oral. São Paulo: Ediçôes Loyola, 1996. FERRARA, Lucrécia D’Alessio. Olhar periférico. São Paulo: EDUSP/FAPESP, 1993. FARIA. Hamilton (org.) Experiências de gestão cultural democrática. São Paulo: Pólis, 1993. WILliANS, Raymond. Cultura. Rio de Janeiro: Paz e Terra, 1992. 
estudos de memória oral no âmbito da semiótica produzem frutos legítimos na orientação de pós-graduandos de diversos pontos do país, os quais precisam encarar a dignidade das expressões populares como resistência, mediação ou, pelo menos, valor aposto aos diversos espaços sociais e em tensão com a produção midiática. E se colocarmos aí a profusão de rádios ilegais, buscando legitimação, mais as recriações grupais de expressões artísticas e folclóricas tradicionais no mundo das metrópoles, teremos um ingrediente a mais para discutir profundamente o sentido das criações orais no mundo metropolitano, talvez a disputa de poderes e a busca de alternativas.

O estudo que se inicia busca exatamente compreender a força ou a debilidade da comunicação oral popular e seu papel no tenso diálogo com o universo mais poderoso da oficialidade escolar, com o currículo imposto pelas autoridades, com a força da comunicação televisiva.

Não convém deixar em branco o fato de que ainda não aquilatamos bem a real profundidade dos embates entre os universos tradicional e moderno (pós-moderno?), enunciados nos trabalhos de Florestan Fernandes e Antônio Cândido ${ }^{2}$ sobre folclore e mudança e sobre o mundo rústico de passagem rural-urbana.

\section{OBJETIVOS}

O que se espera desse estudo em parceria

1. Interessar a comunidade escolar e seu entorno a recolher contos e casos populares para a criação de um banco de memória local.
2. Trabalhar passo a passo o material recolhido, considerando os tipos das histórias e dos casos narrados, forma, enredo, motivos, projeção social.

3. Propor o desenvolvimento de reflexões sobre a matéria memorial vivenciada pelos participantes da recolha (estudantes, professores, extensão comunitária) e o currículo de estudos de primeiro grau, considerando o círculo de comunicação social, os níveis de discurso, as formas de linguagem usadas, convergências e divergências entre a ciência divulgada pelos livros didáticos e a narrativa popular, os conceitos trabalhados e as noções divulgadas popularmente etc.

4. Organizar comunitariamente a matéria memorial e publicá-la, considerando a autoria dos narradores e registradores.

5. Abrir espaço para a constituição de uma dinâmica cultural em que se tornem contínuos e relacionados os atos de ouvir, registrar, elaborar, aproveitar pedagogicamente, produzir encontros e festas, discutir relações entre divulgação científica e memória popular, compreender criticamente os novos modos de viver na cidade informada e enformada pela mídia eletrônica.

6. Criar um banco de dados sobre as culturas populares na cidade, expandir informações do projeto para outros espaços cultural-escolares e buscar o estabelecimento de círculos de comunicação cultural.

\section{Por que voltar a ouvir os narradores?}

Os trabalhos de Roman Jakobson e a metodologia de trabalho do que se convencionou chamar de método Paulo Freire convergem em grau superior: lá onde os estudos de contos populares se encontram com o valor da memória como interpretação da

2. FERNANDES, Florestan. Folclore e mudança social na cidade de São Paulo. 2.ed, Petropólis: Vozes, 1979, CÂNDIDO, Antônio. Parceiros do Rio Bonito: estudo sobre o caipira paulista e a transformação dos seus meios de vida. 4.ed. São Paulo: Duas Cidades, 1977. 
cultura. Quando o professor Dov Noy, da Universidade Hebraica de Jerusalém, organizou (1970/1980) seus grupos de conversa para "lembrarem histórias da diáspora judaica” e, ato contínuo, registrá-las, publicá-las, relê-las em conjunto e trazer à luz outras produzia, de fato, círculos de comunicação-cultura, lugares de palavra geradora em que o direito à voz e à vez de dizer (a maioria vinha de países subdesenvolvidos e de classe social de baixa renda) ensejava novas memórias e engendrava muitas reflexões sobre a vida presente, comparada às formas tradicionais de existência das comunidades judaicas semi-reclusas. De fato, as histórias que Aarne-Thompson classificou em contos de animais, maravilhoso-dramáticos, acumulativos, de humor e de heróis locais compunham um círculo comunicacional, lugar de cidadania por ser espaço de exercício de linguagem, em que as vozes animadas produziam ênfases lingüísticoteatrais no seu relacionamento entre a memória vivida e a memória comunicada.

Assim, as funções fática, conativa, referencial, metalingüística etc. se realizavam, reforçando valores, mostrando mudanças socioculturais, esclarecendo ideologias, destacando universos imaginários e ações sobre o novo espaço de vida.

Tanto era fundamental ver as quantidades de histórias, sinal de preferências culturais localizadas quanto as qualidades de personagens, cenários, enredos, desenlaces e modos de enunciação, pois ali se desenhava o jeito possível de relações sociais estabelecido entre pessoa-família-comunidade e o todo social, quer na terra de origem, quer no espaço de destino. $\mathrm{O}$ trabalho de Haroldo de Campos $^{3}$ sobre Macunaíma, de Mário de Andrade, reflete essa fragmentação de formas que, recolhidas (à maneira cabalística) apontam para uma nova proposta de gênero literário no coração da cultura latino-americana.

Estamos diante do conto e do caso, formas simples em si, mas ricas de significação no seu enredamento social. André Jolles $^{4}$ nos diz que o caso é uma disposição mental que representa o universo como um objeto suscetível de ser avaliado e julgado segundo normas. Assim, casos legais, disputas, acontecimentos passados e presentes ligados à administração governamental, relações sociais da vizinhança no bairro etc. são transformados em casos a merecer sua narratividade, que busca o julgamento público ou ao menos a paz da consciência. Do conto temos a disposição mental que busca o maravilhoso, que ama o natural, o verdadeiro, que quer fazer-se impressão de acontecimento memorável, em que o contar é o acontecer. Assim, essa disposição universal passa por todos nós, de crianças a idosos, quer na base da literatura chamada erudita, quer no contar e recontar anônimos. Sílvio Romero, Basílio de Magalhães, Mário de Andrade, Câmara Cascudo, nossos avós e nossos pais nos educaram nessa disposição mental.

Foi possível verificar essa riqueza quando da realização da pesquisa entre migrantes e imigrantes do Grande $\mathrm{ABC}$ e Baixada Santista, em São Paulo. Nos anos 80 , ali trabalhamos, juntamente com a Prof ${ }^{\mathrm{P}}$. Dra. Jerusa Pires Ferreira, nos anos 80, sobre a memória popular. Essa região se constitui de antigos espaços de passagem que

3. O autor desenvolveu na sua pesquisa de doutorado na Faculdade de Filosofia, Letras e Ciências Humanas da USP, uma teoria da prosa modernista brasileira, embasada na obra Macunaíma, tendo sido publicada em: CAMPOS, Haroldo de. Morfologia de Macunaíma. São Paulo: Perspectiva, 1973. 303p. (N.E.)

4. JOLLES, André. Formas simples. São Paulo: Cultrix, 1976. 
sofreram, a partir do final do século passado, processos de enraizamento do novo sistema de produção. Isso não quer dizer enraizamento do(a) homem/mulher/famí$\mathrm{lia} /$ comunidade. Às vezes dá-se o contrário. No entanto, os discursos e práticas populares da Zona Sul da metrópole paulista produziam dados para a boa comparação com a história e a sociologia: às passagens (18701920) se sucediam as implantações do sistema de produção sucessor à monocultura cafeeira (1920-1950) e a estas o conflito entre capital e trabalho, melhor explicitado nos movimentos sociais dos anos 70/80. Interessante dizer que esses três momentos/movimentos históricos compõem as estruturas dos contos e casos ouvidos e publicados em 1983 e $1990^{5}$. O que se pode dizer das cidades e suas identidades socioculturais é, antes de tudo, um conjunto de valores e tendências já presentes nos intertextos dos discursos. Ora, o espaço de passagem é aquele da aventura, da primeira viagem, da saída e do retorno, da dificuldade de adaptação. Porém, o crescimento da cidade e da família se fazem complexos, exigentes de alguma sedimentação e o processo migrante-imigrante se planta na cidade nova, nos acampamentos que podem se transformar em favelas e cortiços, mas também evoluem para bairros a serviço do sistema industrial de produção. Quando o espaço quase saturado e inundado por problemas ecológicos já se aproxima do pós-industrialismo, decorrem novos problemas, novos movimentos sociais dentro de situações de desemprego, crise salarial, busca de estabilidade no esforço pela cidadania. O fenômeno, de toda a periferia de São Paulo, junta as cidades do $\mathrm{ABC}$ às diversas zonas da Capital, inclusive a região que vai do Ipiranga à
Saúde, servida pela E.E.P.G. Raul Fonseca. Nesse momento a memória se torna mais lancinante, pois através de sua recuperação se reordenam os novos lances de vida na cidade.

Do mesmo modo que a memória popular foi importante para a organização das lutas a favor das melhorias sociais dos bairros na década entre os anos de 75-85, o seu exercício renovado será fator de agregação e reencontro quando novas mudanças se operarem.

$\mathrm{O}$ antigo provérbio oriental nos lembra: "A memória é o pilar da redenção e o esquecimento o princípio da morte".

\section{MEMÓRIA E IDENTIDADE}

Isso não nos faz ignorar as ameaças sobre a própria memória. Antônio Cândido, em seu prefácio à obra de Francisco Assis Sousa Lima, prêmio Sílvio Romero $1984^{6}$, assevera: "Quando a solidariedade de tipo tradicional se esvai, a sobrevivência do conto fica comprometida e a memória se perde. A dissolução da sociedade tradicional levará com certeza ao fim do conto popular, tendo uma etapa de transformação radical sob o impacto dos meios atuais de comunicação". Cabe-nos ver e testar se de fato estamos no ocaso da solidariedade social no contexto da metropolização. Não nos cabe julgar, mas hipotetizar que se transmutam formas, escondem-se virtudes, mas se abre um substrato de novas marcas de solidariedade, em que o tradicional já não é paradigma, mas nas quais o gesto e a palavra não são mortos. Ademais, as formas de recepção da mí- 
dia provavelmente a julguem a partir do seu baú cultural (não somente criado pela própria mídia), produzindo valores e perspectivas que levem em conta a matéria tradicional subjacente. Certamente que a memória introjetada e sem direito à expressão produz conflitos, mas também é verdade que as novas formas de associatividade engendram campos de expressão, fazem-se casos e contos buscando legitimidade social, gestos culturais em vista do indispensável equilíbrio na Metrópole. Aqui é o lugar onde às vezes o impossível se faz possibilidade.

As memórias, para citar textos do tipo cinco da classificação de A. Aarne e S. Thompson ${ }^{7}$, buscam organizar-se na realidade imaginária e imaginada: "Nós chegamos em 1936 como imigrantes, né? Aí fomos trabalhar na fazenda Arara. A situação era muito difícil e não dava pra continuar porque nós éramos muito vigiados (...) Então meu pai resolveu fugir da fazenda (...) Ficamos três dias andando até chegar a Cafelândia (...) Trouxeram nós em Lins para pegar o trem e nós ficamos dormindo três dias na estação (...) Então nós pegamos o trem e descemos na Estação da Luz (...) Foi aí que a vida começou a melhorar um pouco no trabalho." (Natália Konopinkas). "Chegamos em São Paulo, foi logo se espalhando cada um pra um lado, um foi para Santos, outro pra Peruibe, outro pra Vila Prudente e eu fui pra casa de um advogado (...) Quando eu cheguei lá, sua mulher falou: Olha Júlia, aqui você não vai ganhar dinheiro, mas vai aprendendo com as moças da casa e tem comida, dormida e bebida" (Júlia Oliveira). "Eu vim porque achei que aqui é lugar bom, e então, me informaram que era bom, eu vim, e de fato é bom e eu estou até hoje. Eu trabalhava na agricultura. Aqui eu achei melhor, apesar de que já breve, quando eu resolver a minha situação eu vou pra lá. Se Deus quiser. Eu penso que não vou me acabar aqui..." (José Paulino Filho).

Sucedem-se os contos e casos de heróis anônimos, etiológicos e maravilhosos ("Tinha um rei que gostava que todo mundo fizesse o que ele queria...", "Outra vez, uma mulher foi falar com o capitão Antônio Silvino pra pedir justiça..."). O que fundamentalmente desejam dizer as histórias é o que também se busca no cotidiano dos bairros da metrópole: a relativa vitória sobre a desintegração física e simbólica, a intercomunicação de segmentos sociais a produzir a condição de pessoa dentro da associatividade ligada ao trabalho e a busca da autonomização dos saberes e seu uso simbólico, a despeito dos contínuos ataques à autonomia organizada.

A vida dos trabalhadores se nega à submissão e suas memórias querem compor um processo de comunicação capaz de produzir identidade, diminuição de distâncias entre o saber e o fazer, dialetização das estruturas rígidas de comando e obediência, encontro de cidadania.

Aí já nos defrontamos com a declaração de Antônio Cândido e carecemos de pesquisas com bastante presença comunitária para alcançarmos novo patamar de reflexão sobre a matéria popular tradicional na sociedade pós-industrial. Em um diálogo sobre as histórias populares, disse Paulo Freire, assumindo a dimensão educativa do processo: "Nós somos uma sociedade dramaticamente autoritária, quer dizer, o Brasil foi inventado de cima pra baixo e silenciado com seu povo, desde o começo. Aqui, quem sempre teve voz pra falar foi a classe domi-

7. AARNE, Antti; THOMPSON, Stith. The types of the Folk-tale. A classification and bibliography. Helsinki, [s.n.], 1929. 
nante, através de seus representantes, inclusive através do púlpito, da Igreja. Quer dizer, a classe dominante sempre falou, bem ou mal. As classes dominadas deste país, toda vez que tentaram falar tiveram sua voz abafada. De um projeto como esse, nem se pode dizer que devolve a palavra às Marias e aos Pedros cujas histórias foram gravadas e estão hoje postas no papel. O problema não é que vocês devolveram a palavra, vocês acreditaram no direito de expressão e, surpresos e surpresas com a pergunta de vocês, Marias, Joaquins, Carolinas, Josés começaram a contar histórias há muito guardadas, arquivadas na intimidade mais profunda de suas memórias mal tratadas. Guardadas, mas não esquecidas. E não esquecidas porque fazem parte de sua identidade de cultura de classe. Imagino que quando começaram a falar sentiram que não é só um direito, mas também um dever."

\section{O PROFESSOR E O RESGATE DA COMUNIDADE}

$\mathrm{Na}$ medida em que se ensaiam os primeiros passos oficiais para valorizar o trabalho do professor, aumentar em uma ou duas horas a permanência dos estudantes na escola, melhorar a qualidade do ensinoaprendizagem e diversificar a ação educativa, a unidade escolar encontrará sentido para descobrir-se centro cultural, lugar de encontro das práticas do bairro, cujos estudantes são a sua representação e cuja leitura do mundo não pode resumir-se aos livros didáticos ou à informação da mídia, não porque sejam sempre ruins, mas porque lhes falta a densidade da vida concreta do espaço em que se encrava a escola, bem como porque são unidades de discurso que só ganham vida se associadas a outros discursos sociais. Aí entram os contos e casos narrados pela população. Aí a escola assume a cultura. Uma educação culturalizada fará intercâmbio de discursos erudito/popular, para ver que na sua profundidade eles se complementam e dizem da diversidade sociocultural e econômica do país e da gente a que serve a escola.

De outro lado, essa matéria, adequadamente trabalhada, será referência para os estudos de recepção, isto é, como vêem e lêem a TV os estudantes. Aí, a qualidade do lugar-escola: mediado por livros de qualidade criticável (alguns certamente são bons!), ela também se remete às falas da cidade e, na acumulação desses discursos, se coloca dentro e ativamente na sociedade quasemidiática, para descobri-la, quiçá criticamente. Isso vale antes para o professor e, ato contínuo, para o aluno. A história da categoria professor é a do mediador cultural e ele não a desautoriza, mas na prática não encontra instrumentos estimuladores da nova qualidade do seu trabalho. Faltam referências que excedam aos discos da Xuxa, visita ao Playcenter, informações codificadas no livro didático encomendado, a interatividade de pé-quebrado da TV. Ora, a nova qualidade do ato pedagógico somente será possível com a ampliação das referências culturais, com a diminuição dos preconceitos de classe, origem e função social no espaço que deveria curtir a cultura (que é a escola) e com a apreciação franca da diversidade lingüístico-cultural pelos educandoseducadores, ou pelo processo que denominamos ensinagem, onde todos aprendem e ensinam. Cabe urgentemente fazer operacional o que é discurso político-pedagógico. A abertura aos discursos e gestos da comunidade externa à escola poderá ser referên- 
cia para a reflexão sobre autoridade, gestão, organização curricular, prática de ensino, fatos e valores indispensáveis à circulação pelos espaços educativos.

\section{ESCOLA, ESPAÇO DE CULTURA}

A escola não precisa tornar-se um centro cultural formal. Basta que assuma a comunicabilidade da cultura que brota, circula e se reorganiza no seu entorno. Aí se faz cultural e esse é um valor que reclamamos há muito. Os professores da E.E.P.G. Raul Fonseca engajados neste projeto manifestaram claro interesse em caminhar nessa direção. Problematizam, sim, o que lhes falta: informação, orientação técnica, material. Por isso, o trabalho proposto também se justifica.

Os contos e as histórias, matéria básica da pesquisa, são complexos lingüístico-comunicacionais. Compõem o círculo das relações sociais a partir de unidades menores como mitos e lendas. A estes agregam a matéria viva do cotidiano, os heróis reencarnados, as situações individuais e familiares, as correlações políticas.

Por isso, a metodologia da Análise do Discurso, que faz surgir os segmentos de discurso como segmentos do modo de ver e interpretar o social, tanto no travestimento da matéria mais antiga em situações contemporâneas como no próprio uso lingüístico a serviço de segmentos sociais. Ao recuperar e trabalhar analiticamente tais linguagens comunitárias, a escola se recoloca no tempo que explica a evolução social, revê a modernidade e seu esforço de diluição das linguagens em formas amplamente comuni- cacionais e menos diversificadas, bem como pode sair e entrar nos livros didáticos e paradidáticos para ver as transformações operadas pelas leituras socialmente diversas. A análise dos discursos narrativos nos mostrará, como em Pêcheux, Brandão e Orlandi ${ }^{9}$, que a cada formação discursiva corresponde uma formação de sentidos de idéias e o conjunto dos diferentes sentidos nos ajudará a compreender os modos de enunciação dos diferentes materiais, do conto ao livro didático; e mais: do modo de inserção social dos narradores, cujos discursos representam camadas sociais desejosas de representação. Enfim, estaremos trabalhando com processos e condições de produção do discurso e da vida. Ademais, acumularemos matéria viva para trabalhar o ciclo anual de atividades, que pode responder à curiosidade em torno do humor popular, das festas cíclicas, das datas regionais e nacionais, da sabedoria científica e do folclore. Assim, a escola entrará no coração da cultura, do qual jamais deveria ter saído.

Enfim, (para começar) o como fazer comunitariamente, propõem-se os passos:

1. Animação da comunidade escolar e do entorno para a importância da memória, da cultura e das histórias, criando círculos de conversa em que situações da comunicação de massa (programas infantis, de humor, novelas e minisséries) façam ver diferenças e similaridades com outros momentos da vida familiar, do bairro, da cidade. Antigos e novos programas de rádio e TV propiciam comparações úteis e abrem o diálogo. Concomitantemente, as equipes de trabalho estimularão pequenas atividades em que a memória das culturas locais sirva de contraponto para o programa em curso.

9. PÊCHEUX, Michel. Semântica e discurso. Uma crítica à afirmação do óbvio. Campinas: Editora da Unicamp. 1988. BRANDÃO. Helena Nagamine. Introdução à Análise do Discurso. Campinas: Editora da Unicamp, 1991. ORLANDI, Eni Pulccinelli. A linguagem e seu funcionamento. 2.ed. Campinas: Editora da Unicamp. 1987. 
2. A equipe de pesquisa analisa detidamente o currículo para ver os possíveis pontos de intersecção em que se associarão as histórias e o programa regular de estudos.

3. Diálogos regulares com professores e comunidade externa tratam da importância da memória da cultura e suas histórias e apresentam a metodologia para animação e captação dos contos e casos (encontro, demonstração do interesse, registro, uso e devolução da informação).

4. Preparação de estudantes - sempre associados a professores - para os encontros, registros e manutenção da relação com a comunidade participante.

5. Definição, animação e realização de encontros festivos, em que situações do universo trabalhado (memória do bairro, gastronomia, lembranças de festas, medicina popular, relações com o meio ambiente, religiosidade) se projetem nos estudos e culminâncias de atividades escolares e que permitam o enriquecimento do processo de comunicação e dos conteúdos objetivados.

6. Estudos de viabilidade para o incremento de relações entre a escola, o sistema comercial-industrial do bairro e os meios de comunicação existentes, com vistas à divul-

Resumo: $\mathrm{O}$ artigo trata da memória e cultura populares, tendo a Escola como centro de animação da comunidade a que ela serve. Constitui-se em projeto de parceria entre a ECA-USP e a Escola Estadual de Primeiro Grau Raul Fonseca. O objetivo é recolher e analisar contos, casos populares e histórias de vida da comunidade dos arredores da escola, no sentido de resgatá-los como mediadores do processo de leitura dos meios de comunicação e verificar como eles colaboram na construção do espaço da cultura, solidariedade e cidadania que a escola pode ocupar.

Palavras-chave: cultura, escola pública, memória, conto gação da matéria trabalhada e seus produtores, apoio para eventos e parceria na publicação dos resultados, que pode ser semestral.

7. Divulgação de relatórios semestrais, tanto para os colaboradores quanto para a Delegacia de Ensino do bairro, visando à expansão da proposta para outras unidades escolares, para fábricas e comunidades organizadas da sociedade civil.

8. Sistematização dos contos e casos e criação de banco de memória, seguida da análise dos discursos para levantamento do aparato lingüístico, das formações ideológicas, dos encontros entre textos e contextos sociais, base para a reflexão sobre a matéria dos contos e sua importância para o currículo escolar. Abre-se, assim, a possibilidade de devolução à comunidade do seu discurso, objetivando o enriquecimento cultural.

9. Criação de grupo de estudos aberto a professores, membros da comunidade externa e alunos para refletir sobre os modos de comunicação tradicionais e os novos modos de comunicação da sociedade de massa, formas e conteúdos dos livros didáticos em relação às culturas populares do Brasil, metodologia de registro de informações e análise de textos da literatura popular.

Abstract: The article deals with popular memory and culture, having the school as the center of animation for community it serves. This project is a partnership between ECAUSP and elementary school "Escola Estadual de Primeiro Grau Raul Fonseca". The objective is to collect and analyze tales, popular fables and stories relative to the life of the community that surrounds the school, to check how they interact in the media reading mediating process and how they collaborate to build the senses in the culture, solidarity and citizenship spaces.

Keywords: Popular culture, public school, memory, popular fables 